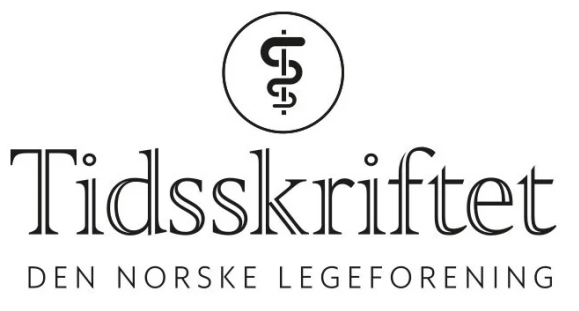

\title{
Forstørrelsesglass på livet
}

INTERVJU

ANNE KATHRINE SEBJØRNSEN

annekaths@hotmail.com

Thorbjørn Brook Steen både synes og høres godt. - Hvis jeg kan ha en stemme i offentligheten, må jeg bruke den der den behøves. For kvinner, barn og de som strever. 


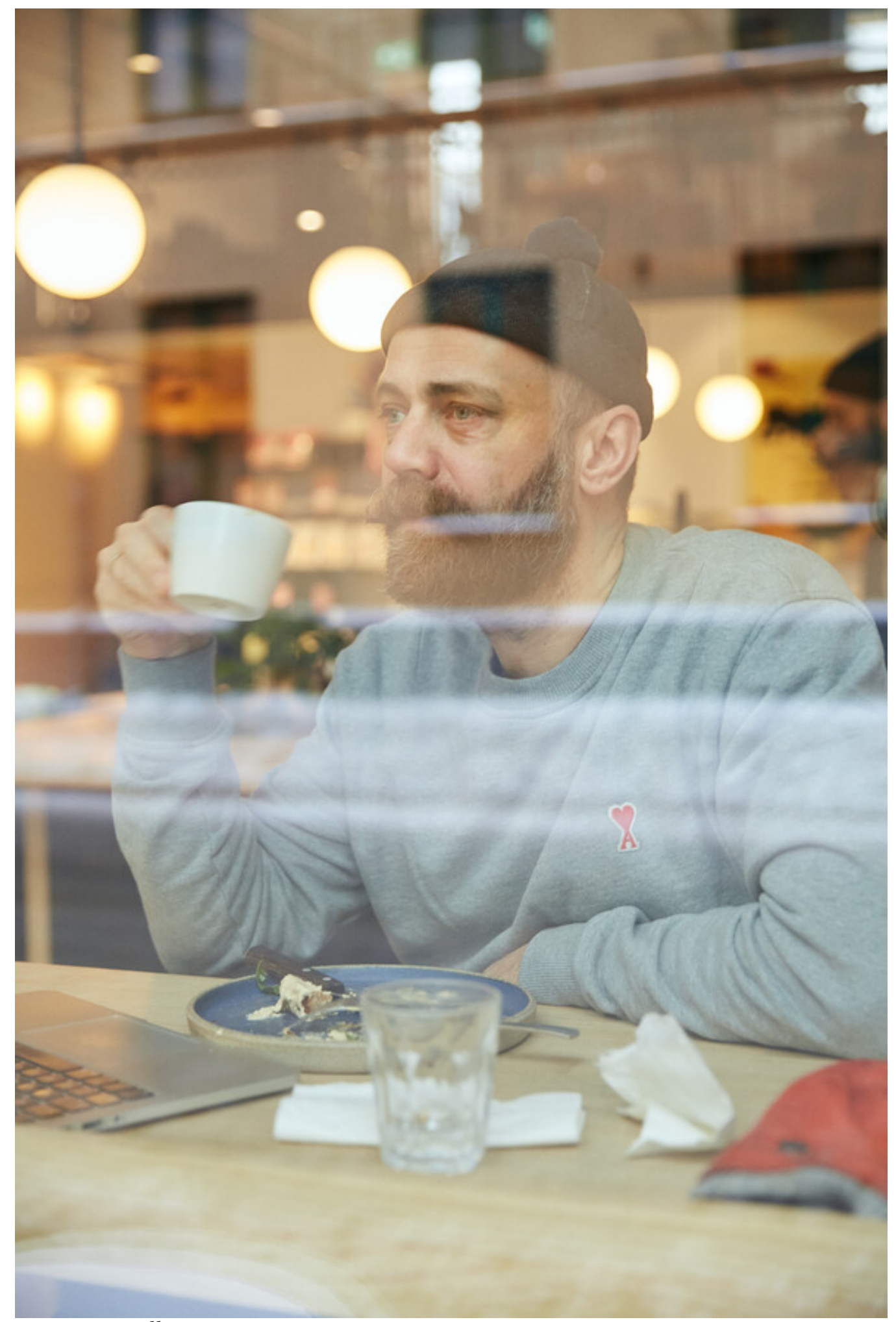

Foto: Birgit Solhaug

Selv i kirurgisk grønt er det en aura av trendy Grünerløkka og håndbrygget kaffe over Thorbjørn Brook Steen. Når han ikke løper rundt i korridorene på fødeavdelingen på Ullevål, treffes han gjerne på Dapper på Løkka, med Macen og en hummussandwich, skrivende på et blogginnlegg eller to. Kreativiteten næres rundt andre skapende mennesker.

- I helgen hadde jeg et blogginnlegg som gikk viralt, utbryter han og setter opp et ivrig gutteansikt.

- Jeg måtte bare formulere en unnskyldning til kvinnene som møtte meg som fødselslege på 20oo-tallet. I min iver etter å få ut ungen, stresset jeg dem jo så mye at de mistet riene. Sånt er det viktig å snakke om! Vi må tørre å innrømme at noe ikke var rett, understreker 
han, og blir taus et brøkdels sekund.

Og innlegget ble behørig likt, delt og omtalt. Det er sånt som gir Brook Steen energikick.

- Jeg blir jo helt overlykkelig når jeg får to hundre likes fra Jordmorforeningen! Det tikket til og med inn to private meldinger fra en som kalte seg «the urban Goddess» i Stockholm. Hvor kult er ikke det?

Nå er strategien en ganske annen når andre bakvakt Brook Steen må inn og assistere på de vanskeligste fødslene. Da dempes belysningen på fødestua, mens han ser kvinnene dypt $\mathrm{i}$ øynene og beroliger med barytonrøst.

- Vi må bygge oppunder kvinnens egen styrke fremfor å overstyre den. Rommets oxytocin er mye viktigere enn det som finnes på apoteket, sier han og retter på callingen.

- Det håndverket jeg utfører, på denne aller tøffeste dagen i et menneskeliv, har betydning i 8o-9o år fremover. Det er både superskremmende og fantastisk spennende!

\section{Forløsningssamtaler}

I snart 10 år har Thorbjørn Brook Steen driftet en poliklinikk hvor sårbare gravide kommer til såkalte «forløsningssamtaler». Engasjementet for gravide som strever har forent obstetrikeren med psykiateren han en gang drømte om å bli. Fødselsangst, traumatiske opplevelser av fødsel og mental helse i barselstid har blitt hans spesiale.

\section{Thorbjørn Brook Steen}

Cand.med., Royal College of Surgeons in Ireland 2001

Spesialist i fødselshjelp og kvinnesykdommer 2011

Overlege Fødeavdelingen Oslo universitetssykehus, Ullevål 2011-d.d.

Kveldspraksis gynekologi og fødselshjelp, Oslo 2020-d.d.

Lektor OsloMet Jordmorskolen 2014-d.d.

Forfatter Kagge Forlag, Nytt liv: alt om svangerskap, fødsel og barselstid (2018) og Hjelp jeg skal føde: fødselslegens råd til den bekymrede gravide (2019)

Spaltist, Foreldre.no 2015-d.d.

Aktiv podkastgjest («Foreldrerådet», «Femihelse», familieliv med mer)

Styremedlem, Sex og Samfunn 2019-d.d.

- Graviditet og fødsel er et forstørrelsesglass på livet. Vanskelig bagasje kan bli nesten umulig å bære hvis ikke veiledningen er god. Det viktigste er å avdekke hva som ligger bak angsten og hvordan tidligere traumer eller mentale lidelser påvirker tanker rundt fødsel og barselstid.

Brook Steen snakker med glød og sprut, på innpust og utpust.

- Mange fødselsleger opplever dette som vanskelig, til og med lite interessant. Jeg er nok en av de fødselslegene i landet som har hatt flest slike samtaler. Jeg er også et stolt medlem av «Ullevål team», forteller han.

«Vi må bygge oppunder kvinnens egen styrke fremfor å overstyre den. Rommets oxytocin er mye viktigere enn det som finnes på apoteket»

Som fersk fødselslege var han mest opptatt av «å vinne debatten» og overbevise kvinnene om at vaginal fødsel var det rette. Han forsto raskt at det bare gjorde vondt verre. 
- Jeg ble en mye bedre fødselslege da jeg sluttet å prøve å overbevise de gravide om mitt syn, og heller begynte å ta del i det sjelelige de opplever. Fødselsangst er ofte et uttrykk for en annen underliggende krise. Er det da riktig at jeg skal tvinge dem inn i det de er aller mest redde for? spør han retorisk.

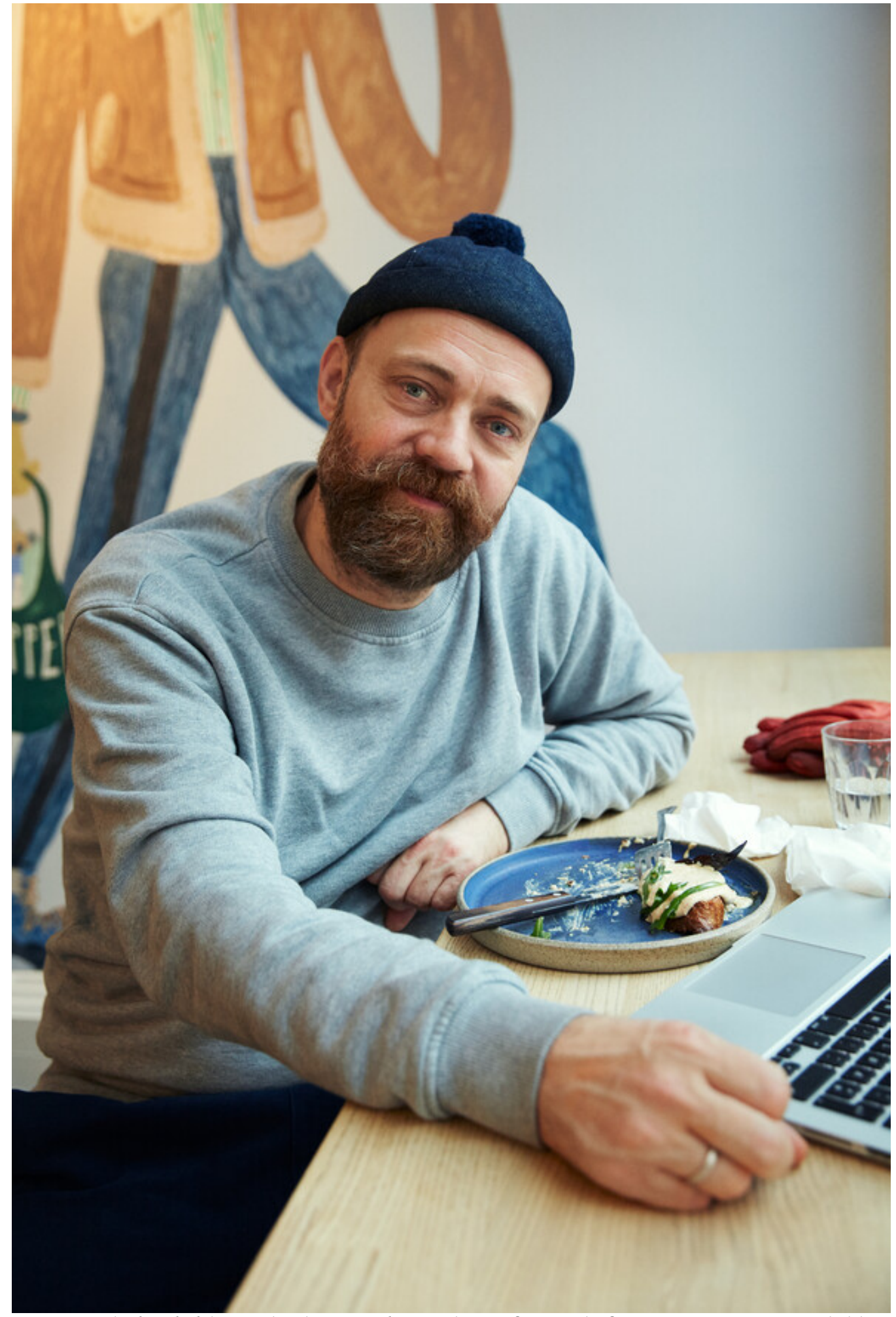

Mang en glødende bloggtekst har sett dagens lys på favorittkaféen Dapper på Grünerløkka i Oslo. Foto: Birgit Solhaug

\section{Den rause bloggeren}


Bak det velutviklede snakketøyet og den fancy barten finnes en fagperson som brenner for å dele kunnskap langt utenfor bygningsmassen på Ullevål sykehus. Han er engasjert $\mathrm{i}$ stiftelsen Sex og samfunn og underviser jordmorstudenter og paramedics.

- Jeg er levende opptatt av å formidle. Faglig, men ikke minst til de gravide. Det viktigste for meg er å nå kvinnene der de er for å opplyse, roe og skape trygghet. Det publikumet er tusen ganger viktigere enn noen som leser en mer eller mindre smal fagartikkel i et høythengende tidsskift. Derfor har det blitt et hav av bloggtekster både i VG og foreldre.no, to bøker og ikke minst det mediet som treffer best, nemlig podkaster. Derfor ble det heller ingen doktorgrad, sier han og smiler.

Dette er en mann som ikke nøler med å dele raust av så vel personlige som faglige erfaringer i offentligheten. Noen ganger litt for mye. Som den gangen han kritiserte besteforeldregenerasjonen for ikke lenger å ha tid til barnebarna, eksemplifisert ved sine egne foreldre. Det fikk moren til å tenne på alle pluggene, og kulminerte i en opphetet diskusjon der moren bannet under direktesending på God morgen Norge på TV2.

\section{"Jeg ble en mye bedre fødselslege da jeg sluttet å prøve å overbevise de} gravide om mitt syn, og heller begynte å ta del i det sjelelige de opplever»

- Etter den mor-sønn-fadesen er det en viss sensur på det jeg skriver fra familielivet, men de ser ofte viktigheten av budskapet mitt. Mye spalteplass går dessuten til å unnskylde alt det dumme jeg gjør som far, og det setter jo barna pris på, sier han og humrer litt.

Thorbjørn Brook Steen gjør ikke noe halvveis.

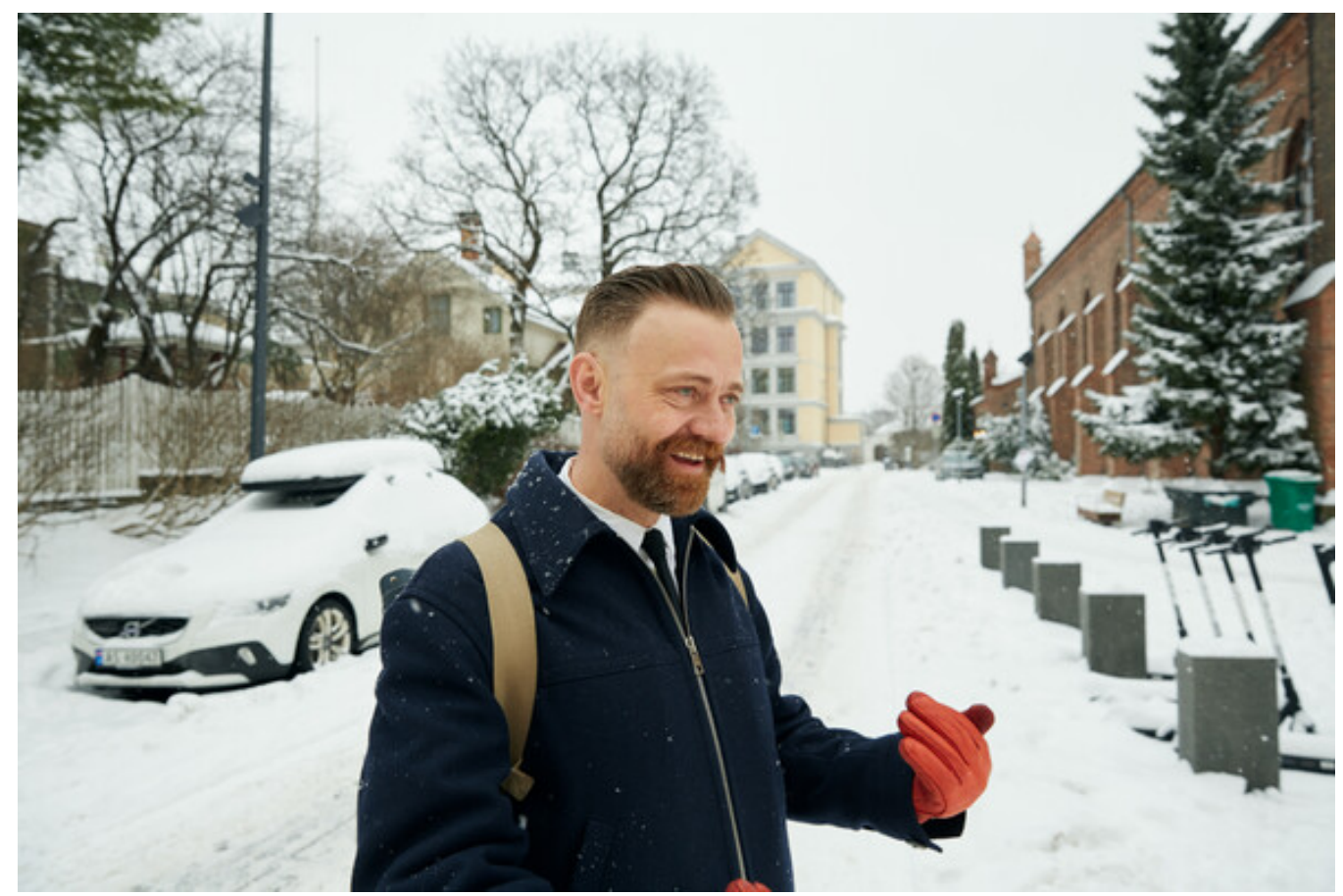

Foto: Birgit Solhaug

- Jeg går «all in» i alt jeg driver med. Det handler ikke om perfeksjonisme, men det må være en pasjon der. Jeg forventer ikke at andre tenker sånn, altså, skyter han inn.

- Hvor rettes lidenskapen ellers i livet?

- Min største pasjon er å lage mat. Jeg kan bruke en hel lørdag til å rusle ned på Vulkan og snakke med slakteren for å finne det perfekte stykket. Jeg blir skikkelig lykkelig hvis den lidenskapen skinner gjennom når jeg lager en syv-retters middag med kalvebrissel og fritert rosenkål til kona eller barna. Min første jobb var faktisk som kokk på Tapas i Hegdehaugsveien. Jeg har et stort behov for å uttrykke meg kreativt, men å lage mat er dessverre det eneste kunstneriske jeg får til, sier han og ler.

\section{Lidenskapelig belastet}


Evnen til å gå fullt inn for det man tror på har gått i arv i generasjoner. Farmor - Eva Steen var blant Norges første kvinnelige gynekologer, og den unge Thorbjørn gjorde ofte lekser på kontoret i privatpraksisen hennes i Skovveien. Bakerst i bokhyllen fant han de underligste bøker med bilder av kvinnelige underliv, og han ble stadig mer nysgjerrig på hva som foregikk i den mystiske gynekologstolen.

- Farmor var en jernkvinne og en pioner innenfor faget. Alenemor og overlege i vaktordning på den tiden, det krevde sitt. Hun har vært forløperen for den enorme respekten jeg har for faget.

Eva Steen levde til Thorbjørn var ferdig med det første året på medisinstudiet.

«Faget er min livsgjerning, men det er ikke livet mitt. Kollegene mine sier

at de skal 'ta en Steen' når de skal gå tidlig, og det må vel vare bra?»

Også faren, professor Petter Andreas Steen, har vært en viktig rollemodell.

- Han har også valgt å tenke annerledes og stå opp for det han tror på. Blant annet var han med på å endre hjerte-lunge-algoritmen, og jeg vil si han har bidratt til å endre akuttmedisinfaget. Faren min har nok i større grad valgt å vie livet til faget enn jeg, sier han.

Han bestemte seg tidlig for at han aldri skulle angre på at han hadde jobbet for mye. Når jobben og litt til var gjort, helst litt tidlig, gikk ferden til barnehagen eller hjem for å lage kakao til jentene. 


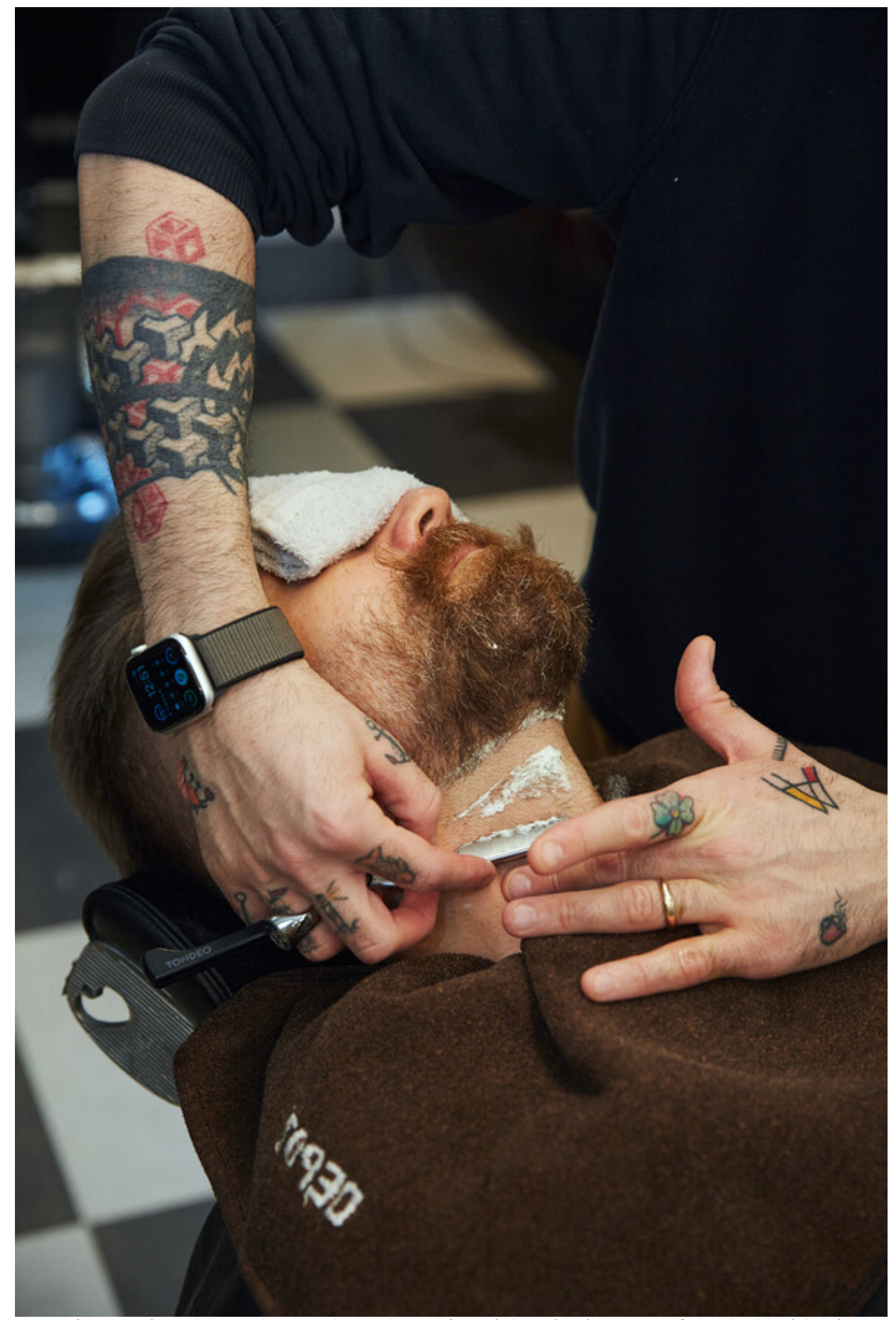

En god snurrebart krever hyppig kontakt med en dyktig barberer. Forfengelighet blir det vennskap og terapi av. Foto: Birgit Solhaug

- Faget er min livsgjerning, men det er ikke livet mitt. Kollegene mine sier at de skal «ta en Steen» når de skal gå tidlig, og det må vel være bra?

\section{En hipster blant de streite}

Thorbjørn var aldri en av de kule gutta. Han hatet fotball, men elsket å henge med jentene. Da han som 13-åring ble invitert til å bo et halvår i Etiopia sammen med en venn og faren hans, var han snar til å gripe muligheten. 
- Det var mitt livs viktigste halvår. Jeg lærte at verden var annerledes, og at det er min jobb å støtte oppunder annerledesheten. Jeg liker å være annerledes, erklærer han.

Løftet han ga seg selv om å være annerledes, har han forsøkt å holde siden.

Første dag på ungdomsskolen på Røa møtte han opp i Mao-uniform, og ble mobbet til han omsider ble akseptert. Så fulgte en periode der han hadde midtskill og deklamerte dikt, samtidig som han solgte Blitzavisa «Smørsyra» og ledet ungdomsgruppa i Røa kirke. På Oslo katedralskole møtte han folk fra hele byen og fant endelig friheten. Han ble leder for elevsamfunnet «Ugla», røkte pipe og lagde fersk pasta til rødvinen på festene. Leksene smugleste han på Nasjonalbiblioteket. Da den høyrøstede Thorbjørn plutselig erklærte at han skulle bli lege, fant faren det nødvendig å bore i motivasjonen. Lege var ikke noe man skulle bli ut ifra arverekken.

- Jeg kommer til å ta den alvorspraten med barna mine også. De kan gjøre hva de vil, bare de gjør noe de brenner for, studerer i utlandet og går «all in» på det de velger, sier han og ler litt av seg selv.

«Kvinner går vel ofte til frisøren for å snakke, gjør de ikke? Jeg bruker

barbereren som terapeut»

Pasjon må det være.

Selv ville han ikke «tråkke rundt som sin fars sønn» på medisinstudiet i Oslo, og søkte studieplass i Irland.

- Under intervjuet spurte representantene fra Irland hva jeg kunne tilføre skolen. Jeg svarte at det eneste jeg var god til var å lage mat, og de repliserte at det var perfekt, for de hadde jo et "Gourmet society».

Så var det bestemt.

- Jeg satt forresten i hovedstyret i ANSA, kommer han plutselig på.

- Du har mye energi?

- Jeg har litt sånn to hundre prosent energi, og det å ha morsomme prosjekter gir dynamikk i livet. Jeg ble frustrert da jeg måtte ha overlegepermisjon. Men den aller viktigste rollen er som ektemann og pappa til fire jenter, det er der jeg legger størstedelen av energien.

Han tvinner lett i barten, finjusterer snurren.

- Jeg er redd for å bli så intens at andre blir slitne av det. Hvis Kristin, kona mi, sier at «nå går engasjementet ditt utover familien", da jekker jeg meg ned. Jeg er ikke i tvil om hva som betyr mest i livet. 


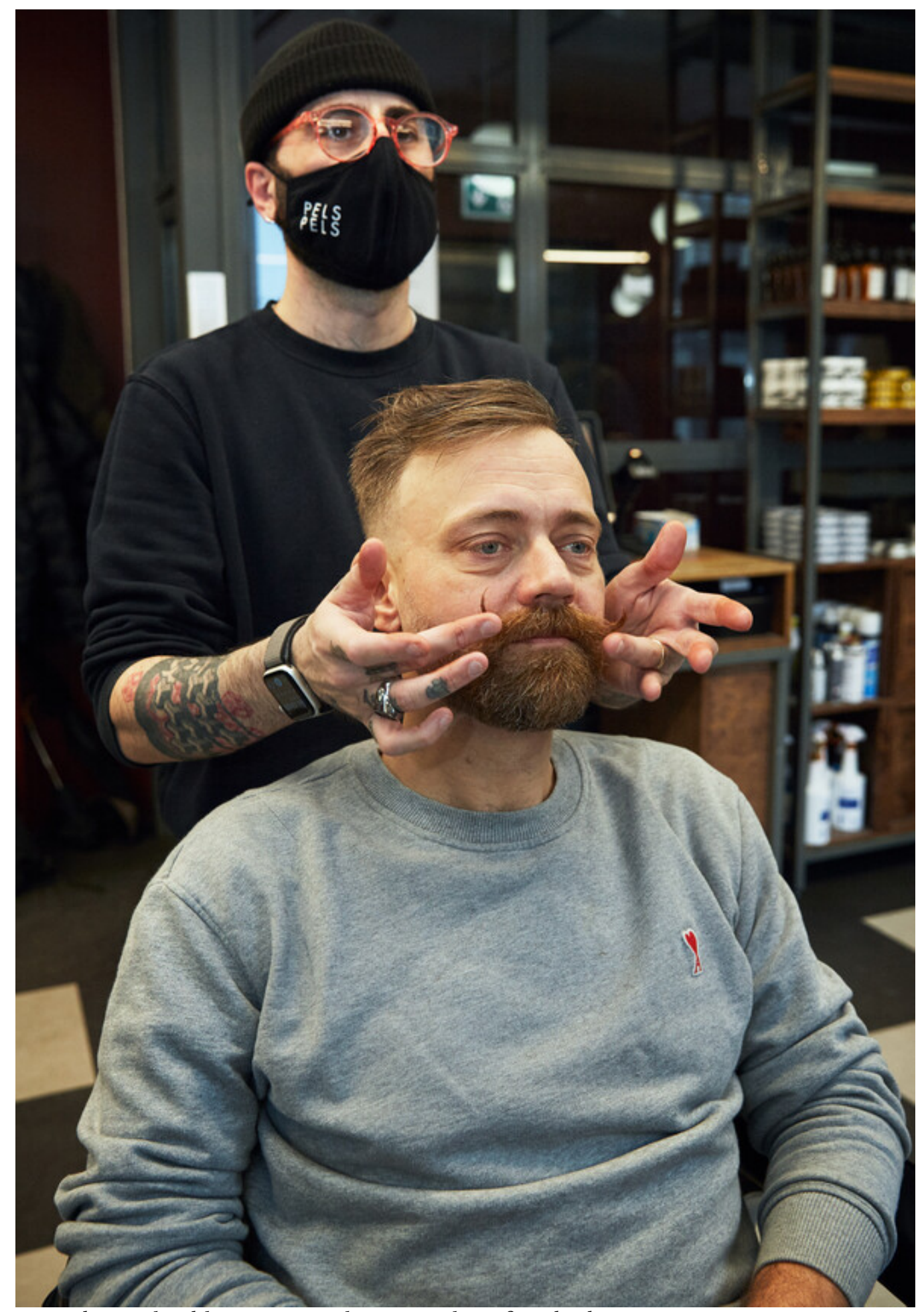

Snurrebarten har blitt et varemerke. Det var hans faste barberer, Maurizio Saccoccia, som mente at Thorbjørn burde ha en bart som pekte oppover. Foto: Birgit Solhaug

\section{Et ansikt som alltid smiler}

Også på sykehuset er han opptatt av mangfoldet. Rengjørerne, portørene og postverten Singh på føde A er blant driverne i sykehusmaskineriet som får for lite oppmerksomhet, mener han.

- Få tar innover seg viktigheten av tverrfaglighet. Det er ikke legene som er navet i sykehusene, understreker han. 
- Kontordama på Sex og samfunn er et eksempel på god tverrfaglighet. Det er hun som får ting til å flyte. Før hun kom dit, jobbet hun på bingoen. Det tror jeg er en veldig nyttig arbeidserfaring.

Også på privaten er mangfoldet det som krydrer hverdagen. Få av vennene er leger, men mange har kreative yrker. Kona er utdannet filmskaper, men jobber som kunstlærer.

- Jeg elsker forskjeller og vil gjerne være annerledes, men har selvironi på det, altså. Barna ler av meg, de både elsker og hater barten.

Snurrebarten har blitt et varemerke. Det var hans faste barberer, Maurizio Saccoccia, som mente at Thorbjørn burde ha en bart som pekte oppover. Da ville ansiktet hans smile, og han ville alltid ha noe positivt ved seg.

- Jeg er jo litt forfengelig, da. Det går mye bartevoks for å holde formen på denne, sier han, og drar frem en litt trist snurrebart.

Munnbind er katastrofe for bartestrukturen.

Så mange besøk har det blitt på PelsPels i Storgata, at den italienske barbereren i løpet av årene har blitt en nær venn. Kona til barberen også.

- Kvinner går vel ofte til frisøren for å snakke, gjør de ikke? Jeg bruker barbereren som sjelesørger, mentor og terapeut. Etter en time hos Maurizio, er jeg sikker på at jeg kommer til en god løsning. Barten ryker den dagen Maurizio sier det er på tide. Jeg lytter til fagfolk.

Publisert: 15. april 2021. Tidsskr Nor Legeforen. DOI: 10.4045/tidsskr.21.0125

(C) Tidsskrift for Den norske legeforening 2023. Lastet ned fra tidsskriftet.no 26. april 2023. 